\title{
Construction and Implementation of a New Intelligent Teaching Model of Business English Based on Constructivism
}

\author{
Hongxia Zhang \\ Taishan University, China
}

\begin{abstract}
Communicating and teaching Business English online are currently in demand. Based on the theory of constructivism, this study takes International Business Negotiation of the Business English major as an example, with the School-Enterprise Cooperation Class that consists of 42 students of the 2018 cohort of a university as the experimental group. Employing certain research methods such as literature review, questionnaire survey, interview, experimental teaching methods, etc., this research constructs and tests out a brand new intelligent teaching model for International Business Negotiation with the goal of enhancing students' practical application abilities in the "Internet+" era, and explores the effect of this model in promoting students' abilities, such as autonomous learning, mobile learning, innovative thinking and practical application of knowledge, etc. This research provides a new, reasonable, and effective teaching approach towards teaching International Business Negotiation and other similar courses of Business English. It provides effective guidance for the reformed teaching of International Business Negotiation, while also giving directions for the reformed teaching of Business English, as well as other foreign languages and courses in the era of "Internet+". At the same time, this research focuses on the working process, which provides practical guidance for students to negotiate efficiently in their future careers.
\end{abstract}

Index Terms-intelligent teaching model, Business English, International Business Negotiation, practical application ability, reformed teaching

\section{INTRODUCTION}

Ever since the concept of "Internet + " was first put forward, it has attracted widespread attention globally. The innovations brought by the internet must be integrated deeply into various economic and social fields, and economic development must now be achieved with the internet serving as both the infrastructure and tool of implementation (Tang Xinghan, 2016). The author of this study, as an instructor of higher education with work experience in corporate settings, attests to the great impact of the internet, considering both the workplace conditions and the activities of graduates. Additionally, as the global economic integration increases continuously, business cooperation between countries is also increasing in frequency and international business negotiation has become an important business activity (Li Yunlong, 2019)."With the increasing participation of Chinese enterprises in international business activities, business negotiation talents have become the most urgently needed talents"(Pu Yan, 2011). The increasingly frequent international business communication has brought higher standards and updated requirements to the teaching of the International Business Negotiation course (Huang Shasha, 2014). Hence, instructors should strengthen teaching research in daily teaching practice and constantly innovate the approaches towards International Business Negotiation teaching in the "Internet +" era in order to cultivate high-quality talents to meet the needs of modern business.

\section{THEORETICAL FRAMEWORK}

Constructivism is a theory explaining how knowledge is constructed in the brain when information comes into contact with existing knowledge that has been developed and accumulated by experience. It has its roots in cognitive psychology, and biology as well as an approach to education that emphasizes the ways knowledge is created in order to adapt to the world (Baidu Encyclopedia, 2021). Constructivism is best known for the constructivist learning theory, which mainly consists of three aspects, including the constructivist perspectives of learning, students, and knowledge (Baidu Encyclopedia, 2021).

The constructivist perspective of learning emphasizes three aspects, namely active construction, social interaction, and situational aspects of learning. As for the first one, active construction of learning, constructivism claims that learning is not a process of transferring knowledge from instructors to students, and students are not merely passive information absorbers but active constructors of information. Students can take the initiative to synthesize, reorganize and transform the existing knowledge and experience in order to interpret the new information, and finally construct the knowledge with their own characteristics. Social interaction of learning, on the other hand, shows that both learners and learning are not isolated but exist in a certain social and cultural environment, and the relevant knowledge is internalized through participation in the social environment. This process is often completed with the cooperation and 
interaction of a learning community, including learners and their helpful scholars, such as instructors, experts, and tutors, etc. The situational aspect of learning mainly refers to the situational nature of learning, knowledge, and skills. It is believed that knowledge cannot exist in isolation, independent from the context of activities, and that learning should be integrated with situational social activities. Knowledge exists in concrete, situational, and perceptive activities, and can only be truly understood through practical application. Therefore, learning should be connected with situational social practice activities and form the corresponding knowledge through the participation of a certain social practice to gradually master the relevant social rules, tools, and activities, etc.

The constructivist view of students maintains that students do not enter the classroom as blank slates. Teaching should not ignore the existing experiences of students and give them brand new knowledge from the outside, but, in a sense, produce new knowledge from the existing knowledge. Teaching is not the transferring of knowledge but the processing and conversion of knowledge. The teacher should not merely present knowledge but should pay attention to students' understanding of various phenomena, listen to their opinions, and explore the origin of their ideas instead. Due to the differences in experience and background, students often have different understandings of problems, and these differences constitute a valuable resource for learning in the student community. Teaching should increase cooperation among students and expose them to different ideas so as to facilitate learning.

The constructivist view of knowledge emphasizes the dynamic nature of knowledge. According to constructivism, knowledge is not an accurate representation of reality, but rather an explanation, a hypothesis, and not the final answer. Knowledge does not accurately reflect the laws of the world; therefore, it cannot be employed casually in response to specific problems, and it should be recreated according to the situation at hand. Although knowledge is granted a certain external form through linguistics and even gains general recognition, it does not necessarily mean that students will have the same understanding of these propositions since these understandings can only be constructed by each student based on their own experiences and background.

Language learning is a process of self-exploration, knowledge construction, and significance coordination based on learners' personal experiences, beliefs, minds, and views. Constructivism is quite rich in that it is student-centered, and it emphasizes students' active discovery and exploration of knowledge. It encourages the active construction of the meaning of learned knowledge instead of just acquiring knowledge through traditional teaching methods, which only involve the transfer of knowledge from the instructors' minds to the students' notebooks (Chen Daozhi, Ling Jinghui, 2021). With its unique theoretical basis, research perspective, and research methods, constructivism has played a critical role in transforming teaching methods, both at home and abroad (Wen Pengnian, Jia Guoying, 2002). It has become the theoretical basis for the integration of advanced modern information technology and teaching in the "Internet +" era.

\section{SigNIFICANCE OF THE RESEARCH}

\section{A. Problem Statement}

Using advanced internet technology to renovate teaching models and approaches has always been an important topic for academic research activities. Foreign language education in China also actively promotes the teaching model supported by internet technology, fully integrated with classroom teaching (Li Chenchen, 2020).Currently, China has practically realized multimedia-assisted classroom teaching and network autonomous learning supported by the internet, such as LAN and network teaching platforms. In recent years, the rapid development of the internet has also promoted the emergence and development of new teaching models such as microlecture, MOOCs, and flipped classrooms. Research on these new teaching models at home and abroad has also promoted renovated foreign language teaching models to a certain extent (Chang Wei, 2019). However, the International Business Negotiation course, which is characterized by strong practicality and application, still has the basic principles and theories as the main focus of the class (Liang Hong, 2016). There are still various problems that must be addressed: How to teach students to use the internet effectively to collect and organize necessary knowledge, and integrate various methods and strategies to deal with people from different cultures, backgrounds, and languages through continuous training and application?

First of all, practice is insufficient. International Business Negotiation is a highly integrated course involving both theory and practice (Li Yunlong, 2019). Ideally, instructors should have a certain amount of practical experience in participating in actual negotiations, as well as a certain amount of international business negotiation ability applicable in real-life scenarios. However, since most instructors are academic research-oriented, and actual experience in corporate negotiations is insufficient, they seldom make use of real-life negotiation experiences to analyze negotiation skills, explain cases of negotiation, and design various negotiation activities for use during the teaching process. In addition, the design of the practical teaching elements of international business negotiation is very complicated; therefore, practical negotiation activities are not as prominent compared to the theoretical elements. In a school environment, it is also difficult for students to truly experience the relevant foreign trade industry knowledge, such as real product knowledge, background information, and industry-related information. Therefore, it is difficult for instructors to fully apply the theoretical knowledge of International Business Negotiation in practical teaching.

Second, internet-based teaching methods are not employed on desirable levels. Multimedia teaching methods do not play their due role, and the independence and innovation of the students are not so good. However, teaching methods have certain advantages, such as enhancing intuitive abilities, which is conducive to understanding concepts and 
methods. It also integrates pictures, texts, sounds, and other images to arouse students' interest in various aspects (Liu Wei, 2019). However, in the actual teaching process, many instructors still turn multimedia into a platform for the presentation of lectures only. The content of teaching, steps to be taken, and students' exercises are arranged in advance by instructors, which leads to students only passively participating in the learning process. In that case, students are in a state of being instilled, and it is difficult to fully bring their own initiatives and innovative abilities into the learning process.

Last but not least, the course has a poor variety of resources, and it is not open to different sources of knowledge. The resources shared with the students are insufficient as there is a single learning resource often. Additionally, the insufficient access to massive information on the internet can hardly support students' autonomous, mobile, fragmented, and exploratory learning among many others.

To sum up, it is imperative to use the internet to enrich students' thinking, make full use of technological advancements and online teaching platforms, and construct a new intelligent teaching model of International Business Negotiation with the goal of cultivating students' practical application abilities in an innovative way in the era of "Internet+".

\section{B. Purposes of the Research}

With the improvement of students' theoretical and practical business abilities as the reference point, this study aims to achieve three changes in the teaching of the International Business Negotiation course. First, the course should be transformed from a traditional theory-oriented course into a new course combining theory and practice. Second, the course should no longer emphasize theory but should emphasize the enhancement of students' negotiation abilities. Third, traditional classroom teaching methods with instructors as the lead should be transformed into flipped classroom teaching methods with students as the lead.

A new intelligent teaching model of International Business Negotiation with the goal of enhancing students' practical application ability must be constructed. Through this new teaching model, this study aims to improve the teaching quality of this course and other courses of Business English and generalize this new teaching model so as to expand the benefits for students and promote the reform of foreign languages teaching and higher education teaching in general.

\section{Innovations}

Utilizing Ding Talk, Tencent QQ, WeChat, and other mobile applications as learning platforms, and with the help of certain teaching models such as microlectures, MOOCs, and flipped classrooms among many others, a new teaching model integrating online learning and offline teaching was constructed to promote deeper integration of advanced internet technology and various new forms of teaching resources. It will also facilitate the full utilization and sharing of massive online resources to achieve the goal of increasing students' enthusiasm for learning, improving their ability of autonomous, mobile, and exploratory learning, and developing their innovative thinking abilities.

This new intelligent teaching model of International Business Negotiation was also constructed with the goal of enhancing students' practical application ability to improve the teaching quality of this course and Business English. It can also further improve students' abilities to apply the knowledge practically and make sure that they are qualified to meet enterprises' demands.

This study makes full use of diverse teaching models and provides a basis for the subsequent reformed teaching of foreign languages and other courses.

\section{MEthodOlOGY}

\section{A. Research Content}

This research focuses on how to use technology and the internet in particular to construct and implement the new intelligent teaching model of International Business Negotiation with the goal of cultivating students' practical application abilities. The contents of the research can be divided into four categories.

First, the current state of International Business Negotiation teaching and the learning of college students were investigated. This includes various problems occurring before, during and after class. The necessity and feasibility of introducing the new intelligent teaching model were explored.

Second, the new intelligent teaching model of International Business Negotiation was constructed and tested with the goal of enhancing students' practical application abilities in the "Internet + " era.

Third, the impact of this new intelligent teaching model on improving students' abilities, including but not limited to autonomous, mobile, exploratory learning, and innovative thinking abilities, was analyzed.

Fourth, the impact of this new intelligent teaching model on improving the comprehensive language abilities as well as practical application abilities of Business English students was analyzed.

\section{B. Objectives}

Business English is the most important communication tool in modern corporate workplaces with foreign funding. For the students of School-Enterprise Cooperation as part of the Business English major, the primary task is to improve their practical language application abilities by using modern means such as the internet. The experimental group of this 
study was the School-Enterprise Cooperation class, as part of the Business English major, which consists of 42 students of the 2018 cohort of a university in the Shandong province. The control group, on the other hand, consisted of the students of the 2017 cohort of the Business major of the same university, taking the same class, with the group size being 54 people. These two classes made use of the same teaching materials had the same instructor, and their English abilities, as well as gender distribution, were similar. Therefore, the conditions for conducting comparative research were met.

\section{Data Gathering and Analysis Methods}

Five methods for data gathering and analysis purposes were employed in total. The first method has been literature review. In accordance with its goals, this study consulted, analyzed, and summarized the constructivism theory and took related literature as its theoretical basis.

The second method has been questionnaire surveys. Before the experimenting phase, the author investigated the current state of International Business Negotiation learning of the students in the control class, including various problems that occurred before, during and after class, and explored the necessity and feasibility of introducing the intelligent teaching model. After the experiment was conducted, the effectiveness of learning and academic performance of the experimental class were analyzed, and all data received were analyzed using SPSS Statistics 26.0 to verify the effectiveness of the proposed intelligent teaching model.

The third method has been to conduct interviews. Based on the final test results of the experimental class, nine students with three different grades were chosen to discuss their feelings and opinions on the intelligent teaching model.

The fourth method has been the experimental teaching method. The intelligent teaching model was implemented for 42 Business English majors of the 2018 cohort taking the School-Enterprise Cooperation class in a university in the Shandong province in order to test its effectiveness.

The fifth method was comparative research. Students' opinions in the questionnaires before and after the application of the intelligent teaching model were compared to verify the impact of the proposed teaching model on their interest in the class and abilities. Moreover, final examination scores of the experimental class and that of the control class were compared to test the effectiveness of this teaching model in improving students' final scores.

\section{Research Process}

The first part of the research process was the questionnaire survey. A questionnaire survey was carried out in the control class consisting of 54 students to find out the current problems that occur in the teaching and learning of International Business Negotiation and their roots, so as to provide sufficient data support for the construction and implementation of the intelligent teaching model. A total of 48 valid questionnaires were received, and parts of the survey results were analyzed as follows:

TABLE 1

PARTS OF THE SURVEY RESULTS

\begin{tabular}{|c|c|c|c|}
\hline Question & Opinion & Number & Proportion \\
\hline \multirow{3}{*}{$\begin{array}{l}\text { How often does the teacher use a variety of internet } \\
\text { teaching methods to carry out the teaching? }\end{array}$} & Often & 4 & $8.33 \%$ \\
\hline & Sometimes & 13 & $27.09 \%$ \\
\hline & Occasionally & 31 & $64.58 \%$ \\
\hline \multirow{3}{*}{$\begin{array}{l}\text { What do you think of the practical teaching process in } \\
\text { the class? }\end{array}$} & Many & 6 & $12.5 \%$ \\
\hline & Appropriate & 13 & $27.08 \%$ \\
\hline & Few & 29 & $60.42 \%$ \\
\hline \multirow{3}{*}{$\begin{array}{l}\text { What do you think of your current autonomous } \\
\text { learning and cooperative learning abilities? }\end{array}$} & Good & 7 & $14.58 \%$ \\
\hline & Average & 30 & $62.5 \%$ \\
\hline & Lacking & 11 & $22.92 \%$ \\
\hline \multirow{3}{*}{$\begin{array}{l}\text { What do you think of your current exploratory learning } \\
\text { ability? }\end{array}$} & Good & 12 & $25 \%$ \\
\hline & Average & 21 & $43.75 \%$ \\
\hline & Lacking & 15 & $31.25 \%$ \\
\hline \multirow[t]{3}{*}{ What kind of role do you play in the class? } & Center of the classroom & 4 & $8.33 \%$ \\
\hline & Knowledge recipient & 28 & $58.34 \%$ \\
\hline & Task completer & 16 & $33.33 \%$ \\
\hline \multirow{3}{*}{$\begin{array}{l}\text { What is the current evaluation system of the course } \\
\text { International Business Negotiation? }\end{array}$} & Teacher evaluation & 35 & $72.92 \%$ \\
\hline & Group evaluation & 6 & $12.5 \%$ \\
\hline & $\begin{array}{l}\text { Common evaluation of teacher } \\
\text { and students }\end{array}$ & 7 & $14.58 \%$ \\
\hline \multirow{3}{*}{$\begin{array}{l}\text { What do you think of your current language practical } \\
\text { application ability? }\end{array}$} & Good & 7 & $14.58 \%$ \\
\hline & Average & 26 & $54.17 \%$ \\
\hline & Lacking & 15 & $31.25 \%$ \\
\hline
\end{tabular}

Through the survey, it was found that $64.58 \%$ of the students thought that the teacher only occasionally used the internet-based means of teaching, which indicates that the thinking model and innovative achievements of the internet and technology had not been deeply integrated into the classroom. $60.42 \%$ of the students believed that there were few practical components of teaching in the classroom, their enthusiasm for participating in learning processes had not been evoked, and their overall negotiation abilities required improvement. $62.5 \%$ of the students expressed that their current autonomous learning and cooperative learning abilities were average, and most of the students thought that their 
exploratory skills were also either average or lacking, which shows that the current teaching methods of the International Business Negotiation course were not adequate in improving students' autonomous learning, cooperative learning, exploratory learning abilities, etc. In class, $58.34 \%$ of the students thought that they were merely the recipients of knowledge, and there was not enough emphasis on engaging students' own initiatives. $72.92 \%$ of the students believed that the current evaluation system was controlled by the teacher, showing that students have not yet taken the lead role in the class, and their senses of existing activities in the classroom and participation require improvement. More than $80 \%$ of the students expressed that their practical language abilities were either average or lacking.

To sum up, within the scope of the International Business Negotiation course, which is supposed to be practical and applicable, students should be taught how to rationally use the internet and relevant technological advancements to collect and sort out necessary knowledge and integrate various methods and strategies. During continuous training and application phases, it was imperative for students to learn to deal with people from different cultures, backgrounds, and languages. Therefore, it was of great significance to construct and implement the intelligent teaching model of International Business Negotiation with the goal of enhancing students' practical application abilities in the era of "Internet +".

The second part of the research process was the construction, implementation, and testing of the proposed new intelligent teaching model. The flipped classroom model was adopted in the pre-class autonomous learning process. Relevant information, such as the latest news and developments in international business negotiations, case analysis and discussion, and activities related to new teaching was shared with the students on social media platforms which were widely used by students, such as Ding Talk, Tencent QQ, WeChat, MOOCs, and mobile learning applications among many others to build platforms for learning the contents of the curriculum, and students could also reprocess the curriculum content according to their own interests and time. The resources that instructors spend a lot of time gathering and handing out before class might not be what students wanted or were interested in, hence the actual impact of such learning materials might be undesirable. For students in the era of "Internet + ", it is quite easy to gather interesting knowledge on the internet and share it in class. Therefore, we should fully respect the needs of students and have confidence in their abilities. Necessary information should be shared with students before class, and tasks should be given ahead of time. Only in this way can students be masters of learning. The students can personally reprocess the learning resources assigned by instructors, and the instructors can also prepare the new lesson initiatively and purposefully.

Opportunities were provided for students to form a student-centered classroom environment and focus more on the practical aspects of the class. Students were allowed to lecture to demonstrate their results and to learn through practice. Classroom teaching was supplemented by simulated negotiations to make students participate in it as real negotiation parties. Thus, they could experience how to talk, experience the impact of their actions during negotiations and observe how the negotiation succeeded or fell through, etc. These factors could largely improve students' professional and practical abilities.

The plan to add practical teaching processes had three steps. First, the group simulated negotiation was organized at any time in class. For example, when talking about face-to-face negotiations or telephone negotiations, two students could act as both parties of the negotiation. In this way, students not only had increased enthusiasm for participation but also showed their shortcomings through the simulations. Therefore, the teacher could analyze the negotiation abilities of students according to the teaching content and tailor the rest of the class accordingly. Second, students were allowed to analyze simulated negotiation cases. When analyzing the case, the instructor should stop at key points to allow the students to think for a moment and put themselves in the position of negotiators to consider how to continue the negotiation. The instructor would temporarily divide the students into several groups to discuss and ask the representative of each group to answer questions. This method not only gave the students a deep impression of the case and created a conducive atmosphere for the students, but also made the students actively think about problems, so as to put the theoretical knowledge into practice. Third, analogue negotiations were simulated. For this kind of formal negotiation, students in the class were divided into several groups, and 6-8 people were in a group to act as the representatives of the two negotiation parties. During the analogue simulated negotiation, the two groups competed against each other. Each group should have a clear division of labor, with clearly defined roles such as the main negotiator, technical expert, businessman, financial personnel, legal personnel, etc. While negotiating, it was necessary to pay attention to the tacit cooperation of the group, and the instructor and other students served as judges.

Hot topics were displayed in the form of microlecture. In practical teaching, hot topics and typical cases were made into microlecture to ensure that the students' own initiatives were engaged, and students were increasingly enthusiastic about participating in the topic discussions.

Evaluation mechanisms integrated by both the instructors and the students were adopted in the evaluation process. First of all, students were given the opportunity to evaluate. In each simulated negotiation, students directly voted and graded the negotiation team using the group voting function in the Tencent QQ mobile chat group of the class, consisting of both instructors and students. The instructors showed the voting results to the students in class, then the results were adjusted according to the instructors' opinions to serve as the students' usual performance scores. This method solved the problem of traditional classes that could not allow all students to participate in the evaluation effectively. In the era of "Internet+", students could become the masters of the class through their smart phones. Online 
voting and grading ensured that their opinions were fully displayed immediately, and everyone could truly feel their status as the masters of the classroom. Second, online testing and data technology were employed to analyze their impact on the classroom. Instructors handed the questions in advance through the established application learning platform or their WeChat official accounts. In the last few minutes of the class, students could log in to answer the questions and submit the answers. Instructors could also display the answers and test results on the screen. Thus, students could know the results of their own learning immediately and intuitively. In this process, instructors achieved more teaching tasks and goals through modern technology, improved the effectiveness of classroom teaching, and timely grasped the dynamic learning of the students, so they could carry out the future components of teaching better.

In the summative evaluation, the effectiveness of students' learning and their academic performances were evaluated in multiple dimensions. The proportion of each part in the final exam should be reasonably arranged according to the attendance rate, simulated negotiations, class discussions, and final quiz of each class, and the assessment of practical negotiation abilities should be highlighted.

This course was taken as an opportunity to explore the model of industry-university-research cooperative development. The teaching results of International Business Negotiation could provide intuitive references for the recruitment of corporations. Therefore, the university could carry out university-enterprise cooperation with interested corporations. Through the study of this course, the process and final learning results of each student could be displayed in an intuitive form, so as to provide a multi-faceted and overall reference for the corporations to improve the efficiency of recruitment. In addition, this course was highly practical, and it was difficult to fully meet the fast development needs of foreign trade corporations by relying on campus teaching alone, which meant that the introduction of new teaching resources was necessary. During the course design, instructors could visit the corporate workplaces to analyze the real practices in international business negotiations, summarize the experiences and lessons of business negotiations, and integrate these real practices into daily teaching, so that the effectiveness of teaching could be greatly improved. During the teaching assessment, it was also favorable to introduce experienced negotiators from foreign corporations to participate in the evaluation of students' negotiation abilities, which not only improves the objectivity of the assessment results but also makes the teaching methods improved and adjusted better.

\section{FINDINGS AND ANALYSIS}

\section{A. Questionnaires}

After the implementation of the new intelligent teaching model for one semester, a questionnaire survey was conducted among the 42 students from the 2018 cohort of School-Enterprise Cooperation class of the Business English major, and a total of 39 valid questionnaires were received. After a semester's study, about $90 \%$ of the students expressed that they view the proposed new intelligent teaching model favorably, and they believed that this novel teaching model had a positive impact on the effectiveness of their learning, especially with the use of various online learning platforms in the era of "Internet +", and that they could get systematic learning resources from multiple channels. It also promoted their abilities of autonomous, mobile, and exploratory learning. 84.62\% of the students expressed that with the new teaching model, they became the master of the classroom, and they could take part in various classroom activities with higher interest, and their cooperative learning abilities and initiative-taking had been greatly improved. $92.31 \%$ of the students expressed that during the continuous training and application, their innovative thinking practical application abilities of business negotiation language and strategy had been greatly enhanced. In short, the intelligent teaching model of International Business Negotiation with the goal of enhancing students' practical application abilities in the "Internet +" era had been viewed favorably and praised by the students.

\section{B. Interviews}

In order to know and confirm the actual situation of students' learning in the experimental class, the author of the study interviewed six students based on the final test results of the experimental class, and they were classified into three categories of assessment: excellent, good, and passed. The interview content mainly focused on the effectiveness of the intelligent teaching model on enhancing their interest in learning, autonomous learning, cooperative learning, exploratory learning, and practical language application abilities, etc. The interview results showed that all the students of the three levels agreed that the new teaching model broke free from the limitations of time and space of traditional learning, and it enabled them to realize fragmented learning and improved their practical language application abilities. The students who passed the exam answered that their confidence and interest were increased, and the completion of the pre-class tasks effectively helped them to interact more in class and improved their ability to internalize new knowledge. Students in the good category said that their learning goals and tasks were clear. Through diversified and systematic learning, their memory of language points was better, and their language skills were constantly strengthened. Students in the excellent category expressed that the teaching content was easy to understand, the students' dominant status in the classroom was reflected, and their practical language application abilities were greatly improved through the classroom interaction between instructors-students, student-students, and common evaluation between instructors-students.

\section{Comparison of Final Tests}


To test the effectiveness of the intelligent teaching model, the author of this study compared the final test scores of the International Business Negotiation course of the experimental class from the 2018 cohort with those of the controlled class from the 2017 cohort. All data received were analyzed by SPSS Statistics 26.0, independent sample ttest was used to analyze the comparison of final scores between the experimental class and controlled class, and the results are shown in the table below:

TABLE 2

COMPARISON OF FINAL SCORES BETWEEN EXPERIMENTAL AND CONTROLLED CLASSES

\begin{tabular}{llllll}
\hline Class & Number & Mean & Std. Deviation & T & P \\
\hline Experimental class & 42 & 84.43 & 5.85 & \multirow{2}{*}{2.589} & \multirow{2}{*}{0.011} \\
Controlled class & 54 & 80.94 & 7.03 & & \\
\hline
\end{tabular}

By analyzing the final test results of the experimental class and the controlled class, it was shown that after the application of the intelligent teaching model for a semester, the final test results of the experimental class had improved significantly. The $\mathrm{P}$ value was 0.011 , and it met the requirement of statistical significance. This indicates that the application of the intelligent teaching model of International Business Negotiation with the goal of enhancing students' practical application abilities was effective and could greatly improve students' English language levels and enhance the quality of teaching.

\section{CONCLUSION}

Based on the theory of constructivism, this research transforms the traditional teaching ideas and constructs a new intelligent teaching model of International Business Negotiation with the goal of enhancing students' practical application abilities in the "Internet + " era. It integrates the modern sciences and technological developments substantially with the current teaching practices of International Business Negotiation of the Business English major, and actively explores the efficiency of this model in promoting students' abilities, such as autonomous, exploratory, and mobile learning abilities, innovative thinking and practical application abilities of knowledge, etc. The current form of the proposed new teaching model has indeed proven to be beneficial, which confirms our confidence in the necessity of actively embracing what the "Internet+" era and technological developments have to offer and of taking the initiative to further reform the teaching methods of foreign languages courses as well as other courses.

\section{ACKNOWLEDGEMENTS}

[Fund Project] The 12th Teaching Reform and Research Project of Taishan University --- Intelligent Teaching Model Construction of International Business Negotiation with the Goal of Cultivating students' Application Ability in the "Internet +" Era , No. 201945.

\section{REFERENCES}

[1] Baidu Encyclopedia. (2021). http://www.360doc.com/content/13/0406/23/11919305_276572629.shtml,(accessed 12/8/2021)

[2] Baidu Encyclopedia. (2021). https://baike.so.com/doc/1411168-1491802.html(accessed 12/8/2021)

[3] Chang Wei. (2019). Application and Exploration of Information Technology in Foreign Language Teaching Reform. Wise Men Discussed Methods, 02, 295-296.

[4] Chen Daozhi, Ling Jinghui. (2021). Online Teaching of Secondary Vocational Education based on Constructivism. Journal of Contemporary Educational Research, 05, 1-7.

[5] Huang Shasha. (2014). Teaching Reform of International Business Negotiation. Curriculum Teaching, 05, 145, 213.

[6] Li Chenchen. (2020). Research on the Reform and Practice of College English Teaching under the Background of "Internet +". Curriculum Teaching, 03, 111-112.

[7] Li Yunlong. (2019). Research on Teaching Reform of International Business Negotiation Based on Flipped Classroom. Heihe Journal, 01,136-141.

[8] Liang Hong. (2016). Reform and Exploration of Bilingual Teaching Method of "International Business Negotiation" under Peer-instruction Teaching Concept. Higher Agricultural Education, 02, 71-73.

[9] Liu Wei. (2019). Reflections on Teaching Reform of International Business Negotiation. Enterprise and Education, 01, 68-69.

[10] Pu Yan. (2011). Research on Teaching Reform of International Business Negotiation. Economic Research Guide, $05,67-69$.

[11] Tang Xinghan. (2016). Innovation and Practice of Teaching Reform of International Business Negotiation in Internet Era. Financial Economy, 01, 34-35.

[12] Wen Pengnian, Jia Guoying. (2002). Constructivist Theory and Teaching Reform-A summary of Constructivist Learning Theory. Educational Theory and Practice, 05, 17-22.

Hongxia Zhang was born in Tai'an, Shandong Province, China. In 2010, she received her Master degree in the field of Foreign Linguistics and Applied Linguistics.

She is currently a lecturer in the School of Foreign Languages, Taishan University, Tai'an, Shandong Province, China. Her research interests include English teaching, translation and conversation analysis. 